\title{
Electrodeposition Coating Process for Automobile Bodies*
}

\author{
By Yoshiaki OYABU,** Nobuo FURUNO,*** Yoji HIRASAWA A** \\ and Hiroshi OMORI****
}

\section{Synopsis}

The earlier electrodeposition process was mainly pursuited for the quality control in terms of mass production. However, the coating efficiency was picked up to be a serial problem from a standpoint of the harmony between natural circumstances and human's living-life conditions and the recovery usage of the paint was earnestly searched. This trend led to the development in various technical fields.

The second impetus on further improvement of electrodeposition paint was due to oil crisis in 1973. The new technology relating to save-energy was developed. In the paint industries, the further improved anti-corrosive performance was strongly demanded. This demand also involved the development of new materials for automobile bodies and even the design of bodies structure.

In this report, the introduction of electrodeposition process into automobile industries in Japan is hystrically reviewed and the electrodeposition mechanism and the mechanism which deposited materials from the coating film are briefly explained. As the demand for anti-corrosive performance is increased, the coating system in which the anodic oxidation and the dissolution from the object metal can not occur, was aimed and recently il was rapidly accepted as the superior system. On the other hand, there is an opposite opinion for this trend on the basis of the metal analysis detected in the deposited film. The characteristics of cationic electrodeposition, in particular, the superior corrosion resistance with regard to the metal dissolution in the whole electrodeposition process is explained.

In Chapter III, throwing power which is characteristic for electrodeposition process is described. It is referred that throwing power is not necessarily determined by the paint performance. Even the electrodeposition coating system, the areas into which the paint liquid does not intrude can not be coated. And it is pointed out that the design of bodies structure is inevitably necessary as well as the improvement of paint performances.

In Chapter IV, the role of the main component, vehicle resin, is introduced. The devices which disperse resin into solvent ' water', and factors which determine the polarity of electrodeposition are explained. And the typical resin structure is shown. The paint performance is greatly effected by the vehicle resin, but it is also deeply related how the paint is produced and how it is coated. Therefore, it is inferred that the paint performances are relatively estimated.

In Chapter $V$, the whole system of electrodeposition coating process is given. The so-called 'closed-loop system' which is remarkably characteristic in electrodeposition process, and which is suitably fitted for mass production of automobile bodies is explained. Besides, the pH control technology of paint bath and the possibility on its future development are referred. The further improvement of the recycle usage technology of paint is pointed out and the possibility to reply for the social needs such as saveenergy and less polution is explained.

In Chapter VI, the present status of electrodeposition process and various technical problems are explained.

The summary of this review and authors' views for future development are given in the final chapter.

\section{Introduction}

The development of the electrodeposition coating technology in automobile bodies industry commenced around 1964 in Japan. In those days, dip coating of water-borne paint was applied to automobile parts after metal pretreatment, and it was confirmed when voltage was applied, the vehicle was deposited at the electrode. This was the beginning of electrodeposition coating. However, the essential point of this technology was not properly comprehended, while the unpublished work was progressing.

Before 1963, the small products to which latex emulsion was mainly applied had been produced industrially. In Great Britain, the first major industrial use of electrodeposition coating system was in 1963 when the Pressed Steel Company commenced priming petrol tanks at their Oxford Works. In U.S.A., the patent on electrodeposition system for automobile bodies and parts such as wheels was published in 1963 from the Ford Motor Company.

And when patents emerged, all the automobile industries aimed at them. As the research was going on, the coating technology was proved to attract us with peculiar interests such as high corrosion resistance of coating and the superior adaptability to mass production.

The paint industries in Japan made a great effort to develop this coating technology, while they introduced it from the developed countries which it was attained in a higher level. The Japanese industries, in particular, automobile industries were in rapid progress, and they invested in the installation for the new coating system. Owing to this days trend, the electrodeposition was satisfactorily accepted by most of automobile industries. And in a short period of time, Japan got ahead of Europe and then U.S.A. in its distribution.

In the beginning of electrodeposition paint which was mainly composed of natural oils, the film performance as a primer itself was inferior to that of solvent-type polyester primer modified with epoxy resin by spray coating, but the electrodeposition coating system was not followed in terms of throwing power and the coating efficiency.

Around 1971, natural circumstances grew worse in proportion to the rapid progress of industrial products and people became sensitive to the recovery of the nature in Japan. The electrodeposition coating system does not emit an organic solvent in the air and in this point of view it fitted the days' demand. How-

* $\quad$ Received April 11, 1983. (C) 1983 ISIJ

** Director of Research Department, Nippon Paint Co., Ltd., Minami-shinagawa, Shinagawa-ku, Tokyo 140.

*** Technical Center, Nippon Paint Co., Ltd., Ikeda-nakamachi, Neyagawa 572.

**** Industrial \& Marine Coatings Division, Nippon Paint Co., Ltd., Fukushima, Fukushima-ku, Osaka 553. 
ever, the great mass of water was utilized for rinsing after electrodeposition and it caused the problem of waste treatment. In response to this problem, the treatment of rinsed water was studied, leading to the development of the closed system.

In 1969, PPG (the Pittsburgh Plate Glass Company, U.S.A.) published the patent on ultrafiltration closed-loop system for electrodeposition coating. The waste treatment of rinsed water after electrodeposition was remarkably improved and coating efficiency reached $100 \%$. This progressed the improvement of the quality and the preparation of large size of ultrafilter and facilitated the industrialization with use of it.

Since the oil crisis in 1973, the textile industries were chased up closely by the developing countries which manufactured products cheaply and they were not allowed to keep the technology for mass production. They were demanded to develop the new technological product being provided specific properties by utilizing their fine chemical technology. It can be said that this trend in the textile industries accelerated the development of ultrafilter.

In 1975, it happened that an automobile engine was dropped off from the body by severe corrosion of supporting panels which was caused by the salt dispersed on the road in Canada. This led to the big compensation and with a help of its impetus the corrosion protection of automobile bodies were taken as the serial problem which had been prone to be neglected and the design of automobile bodies were begun to study in terms of corrosion protection.

Around that time, in order to decrease the weight of automobile bodies, inorganic and organic materials were started to be investigated in response to the days' demand of saving labor and energy and cationic electrodeposition coating attracted remarkable attention.

PPG's patented cathodic electrodeposition system was introduced in 1972. Its first commercial use was for applying the primer on household appliances to gain the advantages of increased detergent resistance and outstanding corrosion resistance.

The corrosion resistance of cationic electrodeposition coating was far superior to that of anionic one and the former was substituted for the latter in a few years in Japan.

In those days, there had been reported only several papers on the steel surface. In the industrial metal pretreatment line which the phosphating bath was controlled in the proper treatment values, even if the satisfied phosphate coating was not obtained due to the variation of steel surface, the phosphating bath was changed to fit the varied steel surface.

Around the time cationic electrodeposition coating was examined to apply to the industrial line, there had been technological competition to protect automobile bodies against corrosion either by the improvement of primer paint or by the development of precoated steel plated with $\mathrm{Zn}, \mathrm{Ni}$, or $\mathrm{Al}$. However, the cationic electrodeposition paint of PPG was proved to be far ahead of others and most of the automobile industries in the world accepted it. Consequently, the anti-corrosive performance of the precoated steel for automobile bodies came to be evaluated by applying electrodeposition coating to it.

Even the steel industries were involved in the world trend from mass production to the development of the functional materials. The steel industries commenced earnestly the development of precoated metal possessing the corrosion resistance, while producing steel by continuous annealing pickling line system. With the development of precoated metal, papers on the analysis and its interpretation on steel surface have begun to appear. (The development of the instrument of chemical analysis has given a big help to them.) And the technology of the phosphate coating has progressed in combination with the technical reports on steel surface.

At present, the electrodeposition system are mainly from PPG's patent. The distribution of primers for automobile bodies in each region is shown in Table 1.

At present it is impossible to decide with technical investigations what sort of steels are suitable for automobile bodies. Though one side and both side galvanized steels have been utilized for automobile bodies, the development of corrosion protection would progress as a total technology while giving answers how to select the precoated steel and how to use it.

The authors inferred that the essential technology for electrodeposition coating system could be throwing power and the control of deposition bath paint, and carried out the analysis of throwing power and the deposition mechanism in 1969. In the references published in the 1960's, electrodeposition coating is described as 'electrophoretic coating'. The authors reported that the film forming reaction was due to water electrolysis, water removal by electroosmosis, aggregation of colloidal particles and their melting by Joules heat.

In this review, the technology of the electrodeposition coating system is discussed on the basis of authors' work and views referring to many papers and patents.

\section{Mechanism of Electrodeposition Coating}

1. Significance of Electrodeposition Coating Process of Automobile Bodies

As structural materials for automobile bodies, steels have been widely utilized as they are supplied cheaply and in large quantities besides their strength. The main purposes of the coating are to protect the substrate from the corrosive attack and to provide it with a good appearance.

Table 1. Distribution of primers in each region. (investigated in 1982, autumn) (\%)

\begin{tabular}{l|rcrc} 
& $\begin{array}{c}\text { U.S.A. \& } \\
\text { Canada }\end{array}$ & Europe & Japan & World \\
\hline Cationic primer & 80 & 53 & 76 & 56 \\
Anionic primer & 1 & 26 & 24 & 20 \\
Nonionic primer & 19 & 21 & 0 & 24 \\
\hline
\end{tabular}


The method of applying primers using the electrodeposition coating process has become quite common in the automobile industry, since it was introduced during the 1960's because of its inherent processing advantages.

The electrodeposition coating method fits well into the coating process in the automobile industry either as an in-line processing method or as an off-line system. The coating time is short, 2 to $3 \mathrm{~min}$ full immersion, for complete bodies or parts, and it coats the exterior, interior, and recessed areas in a single dip application. One technician normally operates the processing system.

Bodies or parts to be coated are fully immersed in the electrodeposition bath. The electrodeposition paint formulated proper materials provides a uniform coating over all electrically conductive surfaces in the given coating time.

The paint is water-borne. There are also small amounts of solvent present, approximately $5 \%$ or less. This composition and the process efficiency are very compatible with goals to minimize air pollution.

When the electrodeposition coating process is used with a 'closed-loop' system, it results in high utilization of the paint. Properly designed systems have a paint utilization efficiency approaching $100 \%$. Most systems are designed to achieve this high efficiency.

There are numerous other characteristics of the electrodeposition process, such as non-flammability. Various reactions relating to electrodeposition in connection with the object are reviewed in this chapter.

\section{Mechanism of Electrodeposition}

In anionic electrodeposition developed in the beginning, it was assumed that the deposition was due to the following reaction, where charged water-soluble or water-dispersible macroion $R^{-}$was changed to $R$ at the anode.

$$
R^{-} \longrightarrow R+e
$$

Resin particles stabilized by macroion is called hydrophobic colloid. The deposition mechanism was assumed to be electrophoretic deposition of hydrophobic colloidal particles and its coating process was called 'electrophoretic coating process'. But, it was failed to explain characteristics of electrodeposition such as superior throwing power and high productivity by the above electrode reaction with an electron transfer.

Many reports including the authors' research ${ }^{\mathbf{1}}$ were published and it was clarified that the deposition mechanism was due to the coagulation of hydrophobic colloidal particles by $\mathrm{H}^{+}$generated by water electrolysis. This result greatly contributed to the development of the cationic electrodeposition coating process. And by the industrial utilization of anionic and cationic electrodeposition, the above mechanism based on electrolysis was widely accepted.

In electrodeposition, charged water-soluble or water-dispersible macroions are attracted by the electrode of the opposite polarity where they undergo electrochemical reactions and are deposited. If the electrodepositing vehicle is represented by $R X$, where $R^{+}$is the macrocation, then $R^{+}$will be deposited at the cathode (cathodic electrodeposition). Conversely, with macroanion $R^{-}$, deposition will take place at the anode (anodic electrodeposition). The anodic electrodeposition relies on carboxyl groups and the cathodic on amine groups. Thus electrodeposition resins are designed and prepared like other coating polymers but are required to carry ion-forming groups, e.g., $-\mathrm{NH}_{2}$ or $-\mathrm{COOH}$. These resins are utilized in electrodeposition as indicated in Table 2.

When the voltage is applied, the main reactions at the electrode are electrolysis of water and the deposition of macroion.

1) Electrolysis of water

Anode

$$
\begin{aligned}
& \qquad \begin{array}{l}
2 \mathrm{H}_{2} \mathrm{O} \longrightarrow 4 \mathrm{H}^{+}+\mathrm{O}_{2}+4 e \\
4 \mathrm{OH}^{-} \longrightarrow \mathrm{O}_{2}+2 \mathrm{H}_{2} \mathrm{O}+4 e
\end{array} \\
& \text { Cathode } \\
& \quad 4 \mathrm{H}_{2} \mathrm{O}+4 e \longrightarrow 4 \mathrm{OH}^{-}+2 \mathrm{H}_{2} \\
& 4 \mathrm{H}^{+}+4 e \longrightarrow 2 \mathrm{H}_{2}
\end{aligned}
$$

2) Polymer deposition

$$
\begin{aligned}
& \text { Anionic electrodeposition } \\
& \qquad R \mathrm{COO}^{-}+\mathrm{H}^{+} \longrightarrow R \mathrm{COOH} \\
& \text { Cationic electrodeposition }
\end{aligned}
$$$$
R_{3} \mathrm{NH}^{+}+\mathrm{OH}^{-} \longrightarrow R_{3} \mathrm{~N}+\mathrm{H}_{2} \mathrm{O}
$$

As shown in Fig. 1, anionic electrodeposition and cationic electrodeposition are similarly symmetry. The mechanism of electrodeposition and others would be substantially considered to be the same phenomena. ${ }^{3)}$

Table 2. Electrodepositable resins and mode of deposition. ${ }^{2)}$

\begin{tabular}{l|l|c|c}
\hline $\operatorname{Resin}^{a}$ & Neutralizer & $\begin{array}{c}\text { Film-forming } \\
\text { macroion }\end{array}$ & $\begin{array}{c}\text { Type electro- } \\
\text { deposition }\end{array}$ \\
\hline$R \mathrm{NH}_{2}$ & Acid (HA aq.) & $R \mathrm{NH}_{3}^{+}$ & Cathodic \\
$R \mathrm{COOH}$ & Base (BOH aq.) & $R \mathrm{COO}^{-}$ & Anodic
\end{tabular}

$a_{R}=$ resin

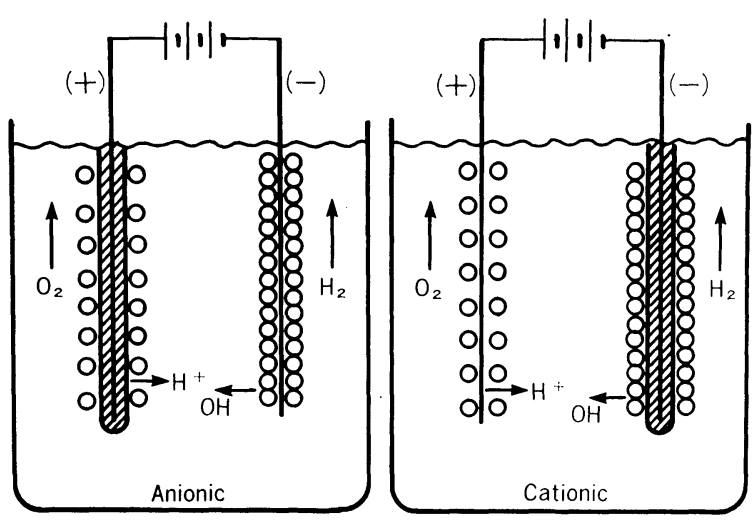

Fig. 1. Comparison of anionic electrodeposition with cationic one. 


\section{Mechanism of Film Formation}

When the constant potential difference $(100 \mathrm{~V})$ was applied, the logarithm of the current was linear to time as shown in Fig. 2. This relationship is called the law of logarithm in the film formation, and indicates that the current decreases due to insulation of the electrode. When the electrodeposition period was longer than $6 \mathrm{sec}$, this relationship deviated from the linear shape and the square of the reciprocal of the current density became linear to time as shown in Fig. 3. This relationship is called the law of parabola in the film formation, and demonstrates that the mechanism of electroconduction of the electrodeposited film is ionic, controlling the rate of the film formation.

From these results the mechanism of the electrodeposition film formation is discussed using the model shown in Fig. 4. When the applied potential difference is low, the melting process of the electrodeposited particles cannot occur. In this case, the particles rinsed off from the electrode by washing with tap

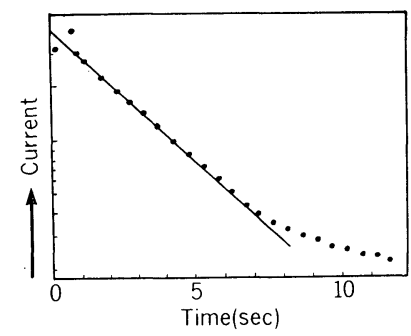

Fig. 2. The relation between the logarithm of current and time during the early period at a constant applied potential of $100 \mathrm{~V}$.

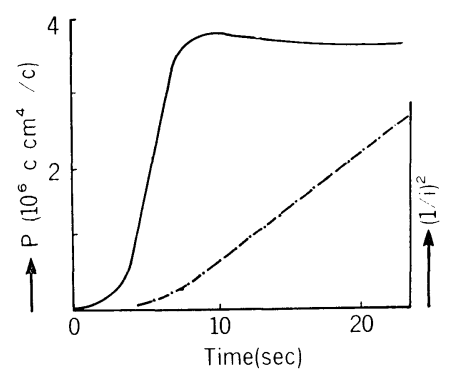

Fig. 3. The relation between the square of reciprocal current and time (-.-), and that between the parameter $p$ and time (-).

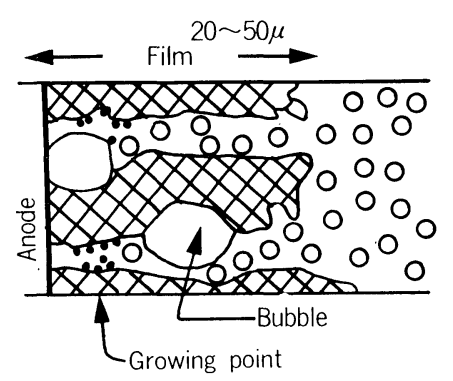

White circles: Dispersed colloidal particles Black circles: Coagulated colloidal particles Hatched area: Insulator

Fig. 4. A model of the electrodeposited film. water after electrodeposition. As the applied potential difference is increased, the melting process occurs faster. Materials formed by this melting process get increased the electric resistance. But it is not allowed to increase beyond a certain value. The film conduction depends on ionic species in the pin holes which are built up by releasing the bubbles. These bubbles and pin holes are visible although they are very small. The colloidal particles precipitate in the pin holes as shown in Fig. 4, the growing point of the film is no longer adjacent to the electrode but within a diffusion layer a finite distance away from the electrode. When the applied potential difference is too high, the random growing ruptures the uniformity of the film. The film rupture voltage is believed to depend on the rheological properties of the film and the rate of electrolysis.

\section{Effect of Metal Dissolution}

When the potential difference is applied in an electrolyte solution, the following metal dissolution may occur at the anode.

$$
M^{0} \longrightarrow M^{n+}+n e
$$

The redox potential of the metal affects the possibility of the above reaction, and as the potential becomes higher, the reaction possibility becomes larger. But this does not imply the continuous reaction progress. When anionic species such as $\mathrm{Cl}^{-}$are presented too much in the electrolyte, the dissolution reaction occurs easily and $\mathrm{CrO}_{4}^{2-}, \mathrm{SO}_{4}^{2-}$ and $\mathrm{CO}_{3}^{2-}$ disturb the above reaction.

In anionic electrodeposition, the object is anodized and the following polymer deposition occurs; that is

$$
n R \mathrm{COOO}^{-}+M^{n+} \longrightarrow(R \mathrm{COO})_{n}-M
$$

In other words, at the anode the dissolution reaction is decreased by the polymer deposition. These reactions would not occur evenly over the automobile bodies, because of their complex-shaped structure. Since the potential difference is not the same in all the locations of automobile bodies, the electrodeposition coating process provides an uneven coating. This would deteriorate the performance of coating such as corrosion resistance and appearance. The dissolved amounts of the metal during reactions differ largely in electrodeposition bath compositions. And they are affected by the surface treatment of the steel. The adaptability of the newly developed metal materials should be strictly examined.

In cationic electrodeposition the object is the cathode, and the above mentioned anodic dissolution reaction does not occur at the object. This point was aimed at and the cationic electrodeposition coating process has been developed which gives an excellent corrosion resistance.

Anderson $^{4}$ analyzed the metal in cationic electrodeposition films and characterized the peculiar relations of cationic electrodeposition against anionic one (Fig. 5). He presumed that the following reaction would occur at the cathode. 


$$
M^{0}+4 \mathrm{OH}^{-}-\left[M \mathrm{O}_{2}\right]^{n-}+2 \mathrm{H}_{2} \mathrm{O}+(4-n) e
$$

Since then, his data have been cited by many researchers with a little discussion. Being based on the results electrodeposition film weight increases with an increase of the deposition time. The authors can not agree with the following approach. The metal detected in electrodeposition film is assumed to be due to the electrode reaction by a flow of current.

Metallic substrate dissolves chemically without current flow. For example, corrosion with hydrogen evolution is illustrated as follows.

$$
\begin{aligned}
& 2 \mathrm{Fe}+3 \mathrm{H}_{2} \mathrm{O} \longrightarrow \mathrm{Fe}_{2} \mathrm{O}_{3}+3 \mathrm{H}_{2} \uparrow \\
& \mathrm{Zn}+\mathrm{H}_{2} \mathrm{O} \longrightarrow \mathrm{ZnO}+\mathrm{H}_{2} \uparrow \\
& 2 \mathrm{Al}+3 \mathrm{H}_{2} \mathrm{O} \longrightarrow \mathrm{Al}_{2} \mathrm{O}_{3}+3 \mathrm{H}_{2} \uparrow
\end{aligned}
$$

These reactions do not participate in electron transfer and they are not related to current flow. These corrosion reactions differ in electrodeposition bath compositions, electrodeposition process conditions, metal materials and their surface conditions. Therefore, the analysis of corrosion reactions are quite difficult. However, the practical difficulties arising from the above mentioned factors have been clarified.

In cationic electrodeposition, the working electrode is the anode and anodic dissolution causes a contamination of electrodeposition bath paint. Care must be taken in cationic electrodeposition being different from anionic electrodeposition. In order to prevent the contamination by dissolved ion, the working electrode is settled inside diaphragm which ion-exchange membrane is preferably used.

\section{Throwing Power}

\section{Significance of Throwing Power in Protective Coating}

In coating applications for complex-shaped automobile bodies, throwing power, the ability to extend paint films into highly recessed areas, as well as the corrosion resistance of coating are greatly demanded. These two specifications have been parallely taken as the index for the improvement and development of the electrodeposition coating process.

Recently, the materials such as the cold-rolled steel, galvanized steel and other steels have been widely utilized for automobile bodies, and the estimation for two specifications (corrosion resistance of coating and throwing power) become complexed and varied. In order to improve the protective performance of automobile bodies, they should be examined particularly in the throwing power. In this chapter, we review in throwing power.

\section{Throwing Power Test}

In case of the design for corrosion protection of automobile bodies, there are two following purposes to estimate throwing power.

1) To design the structure of automobile bodies and materials' adaptability

2) To design electrodeposition paint and deposition coating process

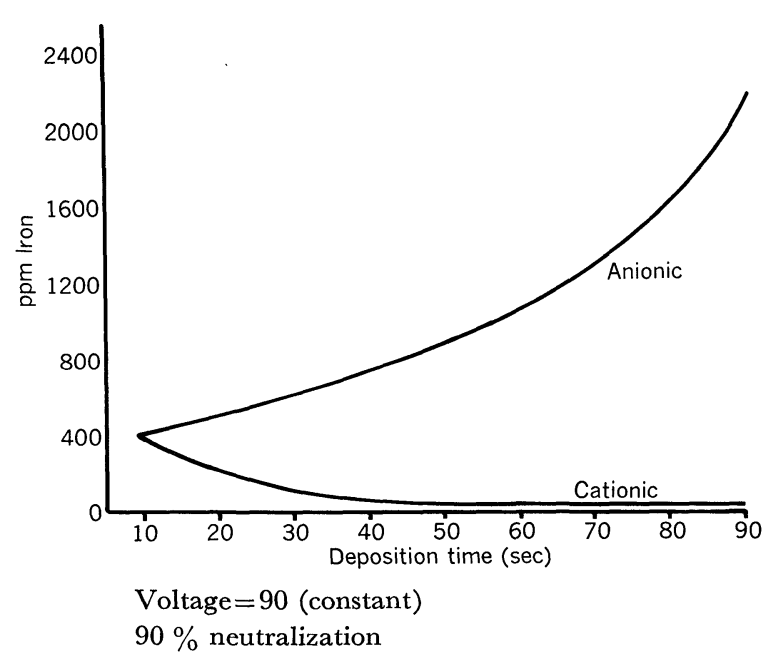

Fig. 5. Changes in iron content of electrodeposited films on cold-rolled steel with deposition time.

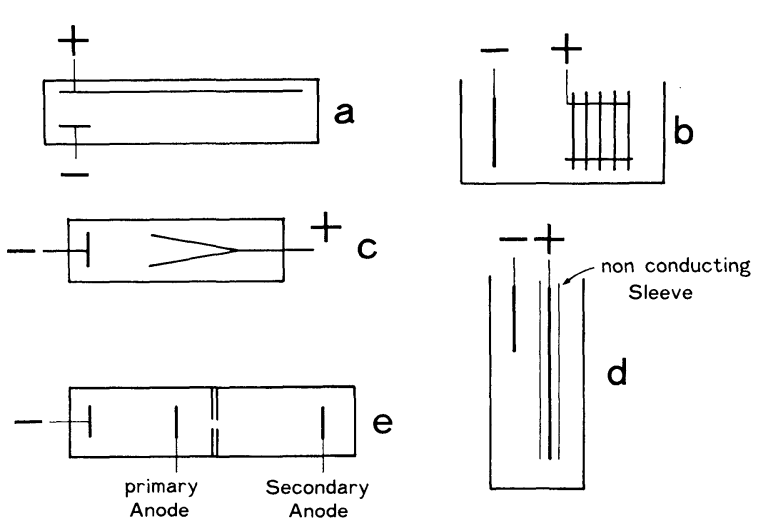

(a) Bar test (plan)

(b) Multiple plate test (elevation)

(c) Wedge test (plan)

(d) Tube test (elevation)

(e) Gell test (plan) [1]

Fig. 6. Types of throwing cells (diagrammatic).

For the first purpose it is recommended to make a model on the characteristics of the bodies structure. The modeling of the bodies structure generally arises from the know-how on the design for corrosion protection of the automobile industry. There have been proposed the following devices for measuring throwing power of the electrodeposition paint since it was developed. The most simple device is a comparative test. Many possible methods were described briefly by Tawn and Berry, ${ }^{5)}$ and are illustrated diagrammatically in Fig. 6. This diagram enables one to appreciate the meaning of throwing power.

(1) Bar test (Fig. 6(a))

In this type of test, either or both of two functions can be measured: the length of the anode coated under given conditions, and the gradient of film thickness down the anode.

(2) Multiple plate test (Fig. 6(b))

In this form of test, the efficiency, that is the weight or film thickness of coating on the inside plates, can be compared with that of coating on the outside plates. 
(3) Wedge test (Fig. 6(c))

In this test, it is only possible to estimate the percentage of the total area not coated with the paint. Mathematical expression of the result is difficult, due to difficulties of measuring areas accurately and defining the boundary between coated and uncoated areas.

(4) Tube test (Fig. 6(d))

Several methods of this type exist, one of which is illustrated in Fig. 6(d), but in essence this is similar to the bar test, except for the restriction applied to the electrical bath by the non-conductive tube itself.

(5) Cell test (Fig. 6(e))

Particular conditions may be applied to the anode in the cathode compartment, and the deposition on the anode in the separate compartment may be determined separately.

Another purpose to estimate throwing power is to detect quantitatively the inherent ability of the used paint. In these several measuring methods, the tube test (Fig. 6) has been recognized to be mostly accepted method. The size of this test tube is defined fully by automobile industries. For examples, Ford Cell and GM Gell are popularly accepted in U.S.A.

\section{Analysis of Throwing Power}

The electrodeposition paint industries have analyzed the mechanism of throwing power as corresponding to the different size of each automobile industry. Oyabu and Furuno ${ }^{6-8)}$ showed that throwing power could be related to the geometry of the test cell and coating properties by the following equation:

$$
T h^{2}=\frac{a}{L} \cdot \frac{E}{J} \cdot \kappa
$$

where, $a:$ the cross-sectional area of the cell

$L:$ the perimeter of the cell

$\kappa$ : the bath conductivity

$E$ : the applied voltage

$J:$ the current density at the coated surface of the tube at the end of the deposition experiment

The equipotential surfaces at the start of the electrodeposition process are shown at the left, and those in progress at the right of Fig. 7. The dense distribution of equipotential surfaces along to the anode corresponds to the electrodeposited film. In this area the current density is approximately uniform.

To verify the relationships between $a$ and $T h$, and between $L$ and $T h$ in the above equations, three kinds of experiments were carried out. A steel panel was inserted into a glass tube. If the thickness of the panel is expressed by $d$ and the width by $l(d \ll l), L$ representing the circumference length of the panel is equal to $2(d+l)$. If the radius of the glass tube is expressed by $r, a$ in the equation is equal to $\pi r^{2}$. Panels of different length $l$ and pipes of different radius $r$ were prepared and combined as shown in Fig. 8.

Case I: $1 / T h^{2}$ should be in proportion to $L$

Case II: Th should be in proportion to $r$

Case III: $\quad$ Th should be in proportion to $r^{\mathbf{1 / 2}}$

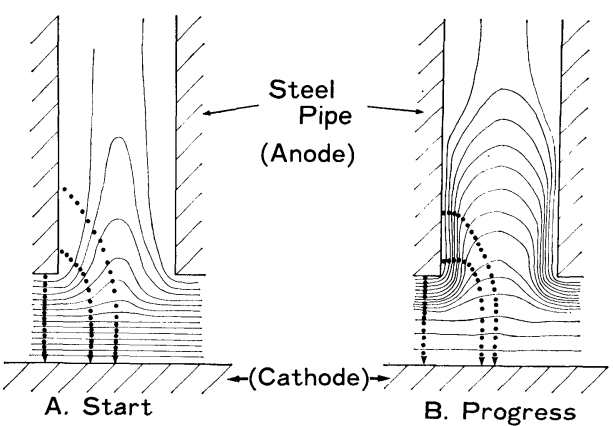

Fig. 7. Models of the equipotential surfaces at the start of electrodeposition process (A) and those in progress (B).

I

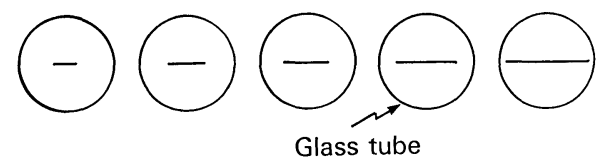

II

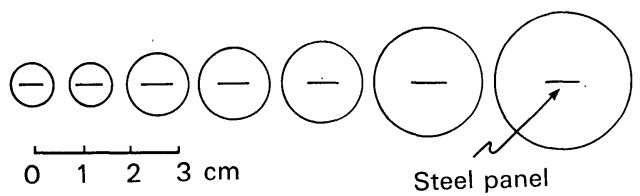

III

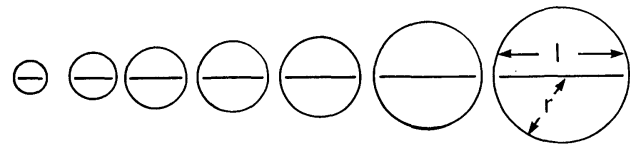

Fig. 8. The sectional view of anodes in the glass tubes used for the throwing power measurement. Cases I to III show the three different combinations of the diameter $r$ of the glass tube and the width $l$ of steel panel.

These panels were electrocoated and the longitudinal length of coated surface, that is throwing power, was measured. These results are shown in Fig. 9.

To estimate the value of throwing power of coating liquids, the steel tube containing a steel panel was coated, and the length of the coated surface of panel, namely the throwing power $(T h)$ was measured. This process is called the tube test method. In Ford Cell, the diameter of the tube $2 r=1.75 \mathrm{~cm}$, the width $l=$ $1.60 \mathrm{~cm}$, and the thickness $d=0.03 \mathrm{~cm}$, and the value of $a / L$ is calculated to be $0.28 \mathrm{~cm}$.

Table 3 is a comparison of some calculated and observed Ford Cell throwing power results. The calculated values were obtained using data obtained from flat panel experiments. Throwing power was determined at the point which the film thickness was 1.7 $\mu \mathrm{m}$. The agreement between the calculated and observed value is reasonably good.

Besides providing good estimates of throwing power, the described equations provide a guide to the factors that must be varied to increase throwing power. Throwing power can be increased by an increase in the bath conductivity and the applied voltage or by an inherent decrease of the final current density.

Pierce and Furuno discussed throwing power tests and the geometric and electrochemical factors which influence those tests in 1975. The results of those analysis permit the calculation of throwing power from electrochemical data obtained on flat panels provided 


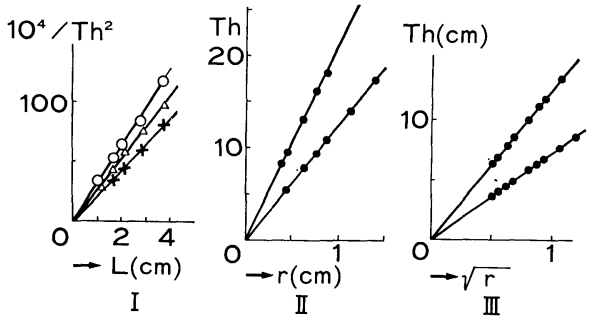

Fig. 9. I. The relation between the square reciprocal of the throwing power $1 / T h^{2}$ and the circumference length $L$ of the panel.

II. The relation between the throwing power $T h$ and the diameter $r$ of the tube.

III. The relation between $T h$ and the square root of the diameter, $r^{1 / 2}$.

I, II, and III corresponding to each case in Fig. 8.

Table 3. Comparison of calculated and observed Ford Cell at $17 \mu \mathrm{m}$ for a pigmented cathodic primer.

\begin{tabular}{r|c|cc}
\hline $\begin{array}{c}\text { Voltage } \\
(\mathrm{V})\end{array}$ & $\begin{array}{c}\text { Time } \\
(\mathrm{sec})\end{array}$ & $\begin{array}{c}\text { Calculated } \\
\text { throwing power } \\
(\mathrm{cm})\end{array}$ & $\begin{array}{c}\text { Observed } \\
\text { throwing power } \\
(\mathrm{cm})\end{array}$ \\
\hline 50 & 90 & 8.6 & 8.9 \\
100 & 90 & 13.0 & 12.4 \\
200 & 90 & 17.8 & 19.0 \\
250 & 90 & 19.2 & 20.6 \\
\hline
\end{tabular}

the geometry, dimensions, voltage, and time of the throwing power experiment are known..$^{\mathbf{9} 10)}$

The progress of this analysis enabled to design the size of the opening space of the body, so as to paint smoothly in recessed areas. And this leads to the design of the automobile structure in terms of corrosion resistance. On the other hand the values of throwing power obtained by different size became possible to compare and this promoted the improvement and development of electrodeposition paint.

In Eq. (1), a/L (cm) means a constant relating to the shape of cell. And when $a / L=0.28 \mathrm{~cm}$, the electrodeposition paint possesses $25 \mathrm{~cm}$ throwing power. The value of $E \cdot \kappa / J(\mathrm{~cm})$ is calculated to be $25^{2} \div$ $0.28=2232 \mathrm{~cm}$. An experimental result of electrodeposition using Halling Cell is given in Fig. 10. It may be understood that the uniform current density is supplied over $20 \mathrm{~m}$. When throwing power over $30 \mathrm{~cm}$ ( $5 \mathrm{~cm}$ increase) is expected, the $E \cdot \kappa / J$ value reaches $3214 \mathrm{~cm}$, indicating $50 \%$ increase $(1.5$ times of $2232 \mathrm{~cm}$ ). It would be a limit to expect a further increase of throwing power. ${ }^{3)}$

\section{Throwing Power Based on Corrosion Protection}

As shown in Table 3, the calculated throwing power does not well consist with the observed one precisely. This is explained as follows; the calculated value is the length of paint film detected theoretically, on the other hand the observed one is the length recognized by naked eyes. And these two values are from different basis.

F. M. Loop ${ }^{11)}$ thought that corrosion resistance

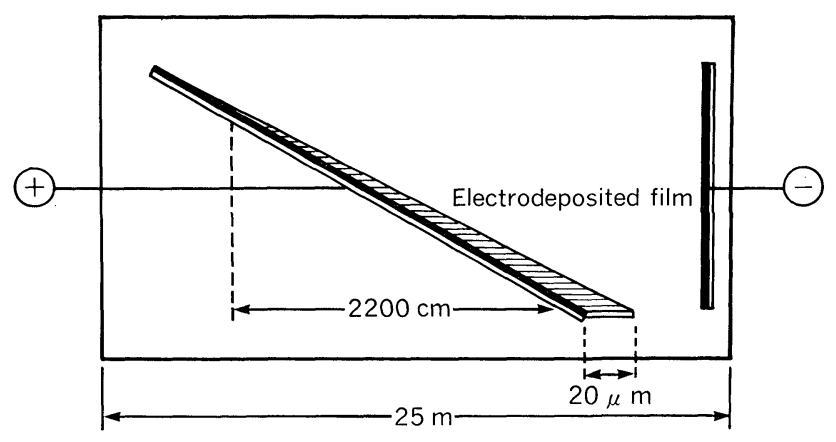

Fig. 10. Halling cell test.

should be evaluated by the length of paint film possessing a certain level of corrosion protection ability. $\mathrm{He}$ proposed that the length of paint film could be measured after being exposed to the corrosion environment such as salt spray test.

\section{Electrodeposition Coating Resins for Auto- mobile Bodies}

\section{Outline}

The resins for electrodeposition coating are classified in water-borne resins. By the balance of hydrophilic and hydrophobic groups, resins are varied to the water soluble type, the colloidal type and the dispersive type. When hydrophilic groups in main chains of macromolecular resins remain in paint films without reaction, the film performance of water resistance would deteriorate. To prevent this deterioration, hydrophilic groups which help to solubilize resins in water, should be introduced in main chains in minimum quantities.

Generally speaking, the average molecular weight of water-borne resins is smaller than that of solvent type resins. Therefore the reaction, by which the higher macromolecules may be formed, should be adapted. It is very important how the reactions are selected to give the excellent film performance. The particles of resin should be ionized in water to give the electrodepositable properties. And the higher the molecular weight of macromolecular ion is, in other words, the higher the average molecular weight per unit ion is, and the larger the deposited film weight per unit electroquantity is.

There are two methods to ionize resins in water. In one method the macromolecules with the acid groups or basic groups are synthesized first, and then, the resin is dispersed in colloidal state or in nearly transparent soluble state by an addition of low molecular basic materials or acid materials. As the macromolecules acid groups is anionic, it is called anionic electrodeposition resin, and as the ones with basic groups is cationic, it is called cationic one.

In the other method, resins being not designed for electrodeposition coating are colloidally dispersed in water chemically or physically by aids of ionic low molecular chemicals such as ionic surface active agents. The resin particles obtained by this method have ionic low molecular groups adsorbed on the sur- 
face of its particles. These particles have the ionic properties. The resin particles with anion are called anionic electrodeposition resin, and the ones with cation are called cationic one. The latter type of resin has been partially applied for the automobile bodies. The reason mainly belongs to the unstabilities of resins in the continuous running of industrial coating line.

\section{Resins for Anionic Electrodeposition Coating}

Resins for anionic electrodeposition coating have carboxylic groups $(R-\mathrm{COOH})$ and are neutralized by bases $(B)$ to make dispersible in water.

$$
R \mathrm{COOH}+B \longrightarrow \mathrm{RCOO}^{-}+\mathrm{BH}^{+}
$$

$R \mathrm{COO}^{-}$is macroanion. Resins for anionic electrodeposition coating used for automobile industries in the beginning were prepared from vegetable oils, thereafter they were partially substituted for synthetic resins such as polybutadiene. Bases $(B)$ were primarily low molecular weight amines such as triethylamine and diethylamine, however in cases potassium hydroxide has been used.

The cure of coating is carried out by oxidation reaction of unsaturated bonds mainly and by crosslinking reaction between melamine or phenol resin and maleinized resin partially.

\section{Oleoresionous Resins}

Oleoresionous resins have a good adhesive performance, pigment dispersibility and storage stability in the paint compositions. When they are used for automobile bodies, strontium chromate is commonly formulated in the primer paint as anti-corrosive pigment. And oleoresionous resins are modified with phenol resin, epoxy resin or styrene-allylalcohol copolymer in order to improve corrosion resistance and throwing power.

\section{Polybutadiene Resins}

The characteristics of liquid polybutadine are good water resistance, storage stability in the paint compositions. The paint film obtained by using it is tough owing to its highly content of unsaturated bonds. There are two kind of commercial products of liquid polybutadiene, in which the polymerization occurs mainly at 1,2 (1,2-polybutadiene) or 1,4 unsaturated bonds (1,4-polybutadiene). When they are applied for electrodeposition paint, they give different advantages. 1,2-polybutadiene has good leveling property and throwing power, but poor corrosion resistance in comparison to 1,4-polybutadiene.

\section{Resins for Cationic Electrodeposition Coating}

The resin synthesis for cationic electrodeposition coating will not be difficult at present. The technologist majored in organic synthesis could prepare various kinds of resins. From the beginning of the 1970's when the electrodeposition coating system was predicted to occupy a large market in the industry, many patents on cationic resins have been claimed. In the design of resins for electrodeposition coating, the following points should be taken into consideration.
1) Polymer design which the deposition compositions are controlled easily

2) Selection of cure reactions

PPG could develop superior resins for cationic electrodeposition due to the good knowledge about the automobile line in terms of operating conditions by the past experiences in the anionic electrodeposition system.

Recently resins for cationic electrodeposition coating were reviewed by Wismer et al. ${ }^{10)}$ and Kordomenos and Nordstorm. ${ }^{12)}$

Resins for cationic electrodeposition coating contain the cationic groups as indicated in Table $4 .{ }^{10}$ ) They were disclosed in many patents.

Acids $(H X)$ are generally organic such as acetic, lactic, etc. The typical crosslinking mechanisms are indicated in Table 5. Usually a trifunctional blocked isocyanate or isocyanate prepolymer was mixed with a hydroxyl or amine functional polymer and then codispersed in water/acid solution. In many cases, half-blocked diisocyanates react with hydroxyl functional back bones resulting in a self-crossling system.

\section{Epoxy Resins}

The most frequently used epoxy groups resins were the well known polyglycidyl ethers of polyphenols such as Bisphenol A. ${ }^{13)}$

In many cases the epoxy resins were modified by the introduction of certain groups or chain extenders to incorporate additional properties which must exist in electrodeposition coating such as high throwing power, flexibility, fast curing, etc.

Table 4. Gationic groups of cationic electrodeposition resins.

\begin{tabular}{|c|c|c|}
\hline & $\begin{array}{c}\text { Cationic groups for water } \\
\text { dispersibility }\end{array}$ & Chemical structure \\
\hline 1. & $\begin{array}{l}\text { Primary and secondary amines } \\
\text { solubilized with acids }\end{array}$ & $\begin{array}{l}R-\mathrm{NH}_{3}^{+} \cdot X^{-} \\
R_{1}-\mathrm{NH}_{2}^{+} \cdot X^{-} \\
\quad R_{2} \\
R_{2}\end{array}$ \\
\hline 2. & $\begin{array}{l}\text { Tertiary amine solubilized with } \\
\text { acids }\end{array}$ & $\begin{array}{c}R_{2} \\
R_{1}-{\stackrel{1}{N} H^{+} \cdot X^{-}}_{1} \\
R_{3}\end{array}$ \\
\hline 3. & $\begin{array}{l}\text { Quaternary ammonium acid } \\
\text { salts }\end{array}$ & $\begin{array}{l}R_{2} \\
R_{1}-\mathrm{N}^{+}-R_{4} \cdot X^{-} \\
R_{3} \\
R_{3}\end{array}$ \\
\hline 4. & $\begin{array}{l}\text { Quaternary ammonium } \\
\text { hydroxides }\end{array}$ & $\begin{array}{l}R_{2} \\
R_{1}-\mathrm{N}^{+}-R_{4} \cdot \mathrm{OH}^{-} \\
\vdots \\
R_{3}\end{array}$ \\
\hline 5. & $\begin{array}{l}\text { Quaternary phosphonium acid } \\
\text { salts }\end{array}$ & $\begin{array}{l}R_{2} \\
R_{1}-\mathrm{P}^{+}-R_{4} \cdot X^{-} \\
\quad \frac{1}{R_{3}}\end{array}$ \\
\hline 6. & Tertiary sulfonium acid salts & $\begin{array}{c}R_{2} \\
R_{1}-\mathrm{I}^{+} \cdot X^{-} \\
1_{3} \\
R_{3}\end{array}$ \\
\hline 7. & $\begin{array}{l}\text { Quaternary ammonium- } \\
\text { carboxylate }\end{array}$ & $\begin{array}{c}R_{2} \\
R_{1}-\mathrm{N}^{+}-R_{4}-\stackrel{\mathrm{O}}{\mathrm{C}}-\mathrm{O}^{-} \\
k_{3}\end{array}$ \\
\hline
\end{tabular}


Table 5. Crosslinking mechanisms of cationic electrodeposition coating.

\begin{tabular}{|c|c|}
\hline $\begin{array}{l}\text { Crosslinking } \\
\text { mechanism }\end{array}$ & Chemical reaction \\
\hline $\begin{array}{l}\text { 1. Grosslinking } \\
\text { with epoxy } \\
\text { groups }\end{array}$ & $\prod_{\mathrm{OH}}+\mathrm{CH}_{2}-\mathrm{CH}-\rightarrow \underset{\substack{\mathrm{OCH}_{2} \mathrm{CH}-\\
\text { OH }}}{\operatorname{OH}}$ \\
\hline $\begin{array}{l}\text { 2. Crosslinking } \\
\text { with blocked } \\
\text { isocyanates }\end{array}$ & 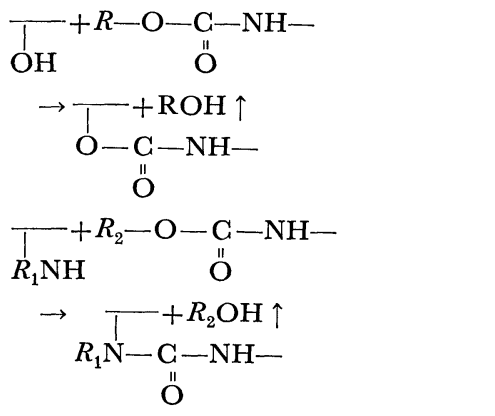 \\
\hline $\begin{array}{l}\text { 3. Crosslinking } \\
\text { with melamine/ } \\
\text { formaldehyde } \\
\text { or phenolic } \\
\text { resin }\end{array}$ & $\begin{array}{l}T_{\mathrm{OH}}+\mathrm{ROCH}_{2}- \\
-\frac{\mathrm{I}}{\mathrm{O}-\mathrm{CH}_{2}-+R \mathrm{OH} \uparrow}\end{array}$ \\
\hline $\begin{array}{l}\text { 4. Crosslinking } \\
\text { via Michael } \\
\text { reaction }\end{array}$ & 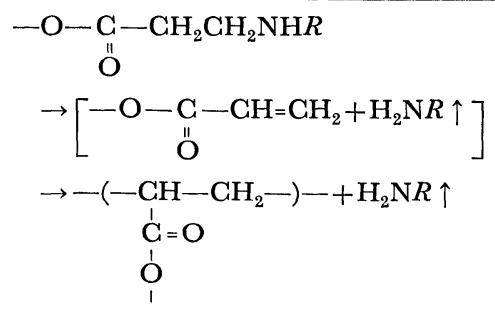 \\
\hline $\begin{array}{l}\text { 5. Thermal poly- } \\
\text { merization with } \\
\text { unsaturated } \\
\text { bonds }\end{array}$ & $-\mathrm{CH}=\mathrm{CH}_{2} \rightarrow-\left(\underset{\mid}{\mathrm{CH}}-\mathrm{CH}_{2}\right)-$ \\
\hline
\end{tabular}

One such modification was described by Jerabek et al. ${ }^{14)}$ in which diepoxides react with polymeric diols to obtain chain extended epoxy resins.

Both polyester and polyether diols were used as the chain extenders. The improvements claimed for these extended epoxy resins were higher rupture voltage, improved flow, coalescence, and flexibility.

Polycondensation products of epoxy resins synthesized by Marx and Gulbins ${ }^{15)}$ using p-hydroxyacetophenone were further reacted with formaldehyde and a secondary amine.

It was claimed that these polycondensation products had superior adhesion and corrosion protection properties in comparison to conventional epoxy resins.

\section{Mannich Bases}

A series of patents ${ }^{16)}$ describe the resin systems suitable for cationic electrodeposition which are Mannich bases derived from the reaction of condensed phenolic compounds with hydroxyl containing secondary amines and formaldehyde.

\section{Urethane Resins}

Matsunaga et al. ${ }^{17)}$ was the first to synthesize cationic thermosettable urethane resins.

\section{Resins Gontaining Unsaturated Bonds}

Unsaturated fatty materials, such as linseed oil or polybutadienes have been maleinized followed by the reaction of dialkylaminoalkyl amines to form amine functional malemides. ${ }^{18)}$

An epoxidized polybutadiene was reacted with an amine acid ${ }^{19)}$ to yield an oxidizable resin system which was deposited at the cathode.

\section{Film Performances of Electrodeposition Coating}

In Table 6 are the typical properties of the anionic and cationic electrodeposition paints produced.

\section{Corrosion Resistance of Electrodeposition Coating}

\section{Corrosion of Automobile Bodies}

The paint film of cationic electrodeposition coating for automobile bodies provides the superior anti-corrosive performance. In corrosive environments rusts of following four types are sometimes observed on the coating surface and the steel surface of automobile bodies.

1) Uniform corrosion

2) Crevice corrosion

3) Pitting corrosion

4) Galvanic corrosion

Uniform corrosion is observed on the outside of automobile bodies and the inside of closed parts such as doors or rocker panels. The corrosion generated on the coated outside of bodies are due to the decrease of the isolation ability of films from corrosive environment, that is the increase of permeability of oxygen and water. The electrodeposition film in the inside of closed parts can not extend beyond the limit of throwing power, and moreover paint is not accessible to complete closed parts.

Crevice corrosion is observed on the uncoated parts (the hemming parts of hoods, doors and trunk lids, etc.), in which steel plates are twofold. The paint can not give access to steel surface of these closed parts.

Pitting corrosion is observed on the defect part of film. (The damaged area caused by the impact of pebbles or scratched area reached to steel surface.) The rust generated around the defect part becomes often scabbed. This rust is sometimes called scab corrosion.

Galvanic corrosion is observed at the contact part of two different metals. (e.g., the part being fixed embrame)

\section{Improvement of Gorrosion Protection of Electrodepo- sition Coating}

The concept of corrosion protection by electrodeposition coating is shown in Fig. 11.

\section{Engineering Process of Electrodeposition Coating}

\section{Metal Pretreatment}

The metal pretreatment prior to electrodeposition coating is inevitable to enhance the paint film performance. The metal of the object is in general easy to form oxide compounds and deoxidizing treatment is essential. When the metal is covered by oil, the first process of the metal pretreatment is degreasing. The main purpose of priming is to protect the substrate metal against corrosion. The primer intercepts 
Table 6. Properties of anionic and cationic electrodeposition paints.

\begin{tabular}{|c|c|c|c|c|c|}
\hline Performances & \multicolumn{2}{|c|}{ Test items } & $\begin{array}{l}\text { Cationic electro- } \\
\text { deposition coating* }\end{array}$ & $\begin{array}{l}\text { Anionic electro- } \\
\text { deposition coating** }\end{array}$ & Note \\
\hline Bath paint properties & \multicolumn{2}{|c|}{$\begin{array}{l}\text { Total solids }(\%) \\
\quad \mathrm{pH} \\
\text { Liquid conductivity }(\mu \mathrm{S} / \mathrm{cm}) \\
\text { Applied voltage }(\mathrm{V}) \\
\text { Applied time }(\mathrm{min}) \\
\text { Coulomb efficiency }(\mathrm{mg} / \mathrm{C}) \\
\text { Film thickness }(\mu \mathrm{m})\end{array}$} & $\begin{array}{l}18 \sim 20 \\
6.2 \sim 6.7 \\
900 \sim 1500 \\
250 \\
3 \\
35 \\
20\end{array}$ & $\begin{array}{l}12 \sim 14 \\
8.5 \sim 9.0 \\
1800 \sim 2100 \\
250 \\
3 \\
23 \\
20\end{array}$ & \\
\hline \multirow[t]{3}{*}{$\begin{array}{l}\text { Electrodeposition film } \\
\text { peformance }\end{array}$} & \multicolumn{2}{|c|}{$\begin{array}{l}\text { Baking schedule } \\
\text { Pencil hardness } \\
\text { Cross cut } \\
\text { Impact resistance } \\
\text { Water resistance } \\
\text { Alkali resistance } \\
\text { Chip resistance }\end{array}$} & $\begin{array}{l}30 \mathrm{~min} \text { at } 170^{\circ} \mathrm{C} \\
3 \mathrm{H} \\
100 / 100 \\
\text { pass } 50 \mathrm{~cm} \\
\text { pass } 500 \mathrm{~h} \\
\text { pass } 240 \mathrm{~h} \\
\text { Good }\end{array}$ & $\begin{array}{l}30 \mathrm{~min} \text { at } 170^{\circ} \mathrm{C} \\
\mathrm{H} \\
100 / 100 \\
\text { pass } 50 \mathrm{~cm} \\
\text { pass } 500 \mathrm{~h} \\
\text { pass } 48 \mathrm{~h} \\
\text { Good }\end{array}$ & $\begin{array}{l}1 \mathrm{~mm} \text { width } \\
1 / 2^{\prime \prime} \phi, 500 \mathrm{~g} \\
\text { dipping at } 40^{\circ} \mathrm{C} \\
0.1 \mathrm{~N} \mathrm{NaOH} \\
\text { Gravelometer }\end{array}$ \\
\hline & \multirow{2}{*}{$\begin{array}{l}\text { Salt spray } \\
\text { resistance }\end{array}$} & (Degrease) & pass $240 \mathrm{~h}(10 \mu \mathrm{m})$ & $24 \sim 48 \mathrm{~h}(10 \mu \mathrm{m})$ & $\begin{array}{l}35^{\circ} \mathrm{C}, 5 \% \mathrm{NaCl} \\
\text { (Film thickness) }\end{array}$ \\
\hline & & (Zn-phosphate) & pass $1000 \mathrm{~h}(20 \mu \mathrm{m})$ & pass $400 \mathrm{~h}(20 \mu \mathrm{m})$ & $\begin{array}{l}\text { within } 3 \mathrm{~mm} \\
\text { Scribe creep }\end{array}$ \\
\hline $\begin{array}{l}\text { System film } \\
\text { performances*** }\end{array}$ & \multicolumn{2}{|c|}{$\begin{array}{l}\text { Cross cut } \\
\text { Impact resistance } \\
\text { Water resistance } \\
\text { Chip resistance } \\
\text { Salt spray resistance }\end{array}$} & $\begin{array}{l}100 / 100 \\
\text { pass } 30 \mathrm{~cm} \\
\text { pass } 240 \mathrm{~h} \\
\text { Good } \\
\text { pass } 1000 \mathrm{~h}\end{array}$ & $\begin{array}{l}100 / 100 \\
\text { pass } 30 \mathrm{~cm} \\
\text { pass } 240 \mathrm{~h} \\
\text { Good } \\
\text { pass } 400 \mathrm{~h}\end{array}$ & $\begin{array}{c}1 \mathrm{~mm} \text { width } \\
1 / 2^{\prime \prime} \phi, 50 \mathrm{~cm} \\
\text { dipping at } 40^{\circ} \mathrm{C} \\
35^{\circ} \mathrm{C}, 5 \% \mathrm{NaCl}\end{array}$ \\
\hline
\end{tabular}

* Powertop U-30

** Powercoat No. 9000

*** Zincphosphating + Electrodeposition + Surfacer + Top coat

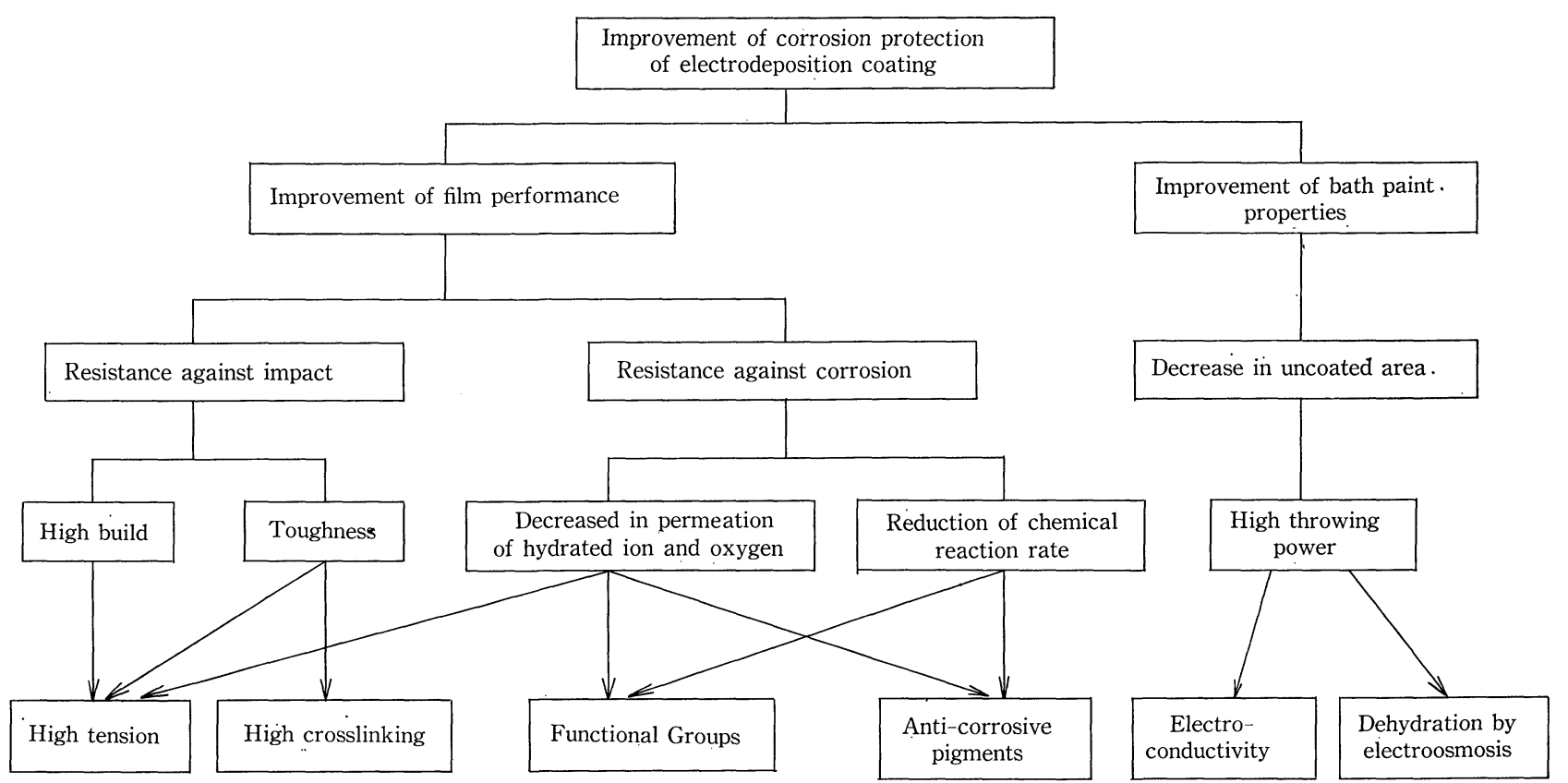

Fig. 11. Concept of corrosion protection by electrodeposition coating.

to contact the metal with corrosive materials.

After phosphating, the excess phosphate solution must be rinsed off with enough water in order to prevent the electrodeposition tank from contaminations.
The performance of electrodeposition coating should be evaluated as the hybrid coating containing the metal pretreatment. An example of the total coating process is given schematically in Fig. 12. 


\section{Paint Recovery from Rinsed Water}

In electrodeposition coating, the excess paint which does not contribute the film forming should be rinsed off to give a good film appearance. If the rinsed water is discarded, it may cause water pollution. In order to prevent this, the automobile bodies after electrodeposition are rinsed off by multiple water rinsing process and the rinsed water is returned to the prior rinsing water tank in regular order. Some of the rinsed water containing the highest content of paint (just after electrodeposition) is returned to the electrodeposition tank. This process enhanced the efficiency of its water utilization and decreased the purged water. Here, the electrodeposition tank is not permitted to be diluted by the rinsed water. There fore, the water amount corresponding to the evaporation is allowed to supply. If the paint is condensed by some device, it is permitted to supply water corresponding to the condensation amount. Hence, the ultrafiltration technology was introduced. And the system utilizing the ultrafiltrate as rinsing water was developed and the problem mentioned above was dissolved. In the perfect closed system, it is ideal that the quality of rinsing water at the final rinsing process is solvent ' water' itself. In the condensation process, reverse osmosis which allows to pass only water and low molecular weight solvent in the theoretical basis is superior to ultrafiltration.

However, in the industrial electrodeposition coating line, the paint varies during electrodeposition and is involved in contaminations, leading to the deterioration of the film performances. To prevent this, the paint is expected to renew as early as possible either by the continuous discard of the rinsed water or by the utilization of the paint at the earliest time. This is why the electrodeposition system has been industrially utilized for the mass production.

In the closed system mentioned above, it can be said that the closed system is allowed to fit the technology to keep the film performance at a certain level. As shown in Fig. 13, the drain pipes are installed at tank to remove undesirable materials. ${ }^{10)}$ The perfect closed system implies the perfect control of the maintenance of the paint relating to the film performance and the possibility of the infinite utilization of the paint. If this is accomplished, the electrodeposition
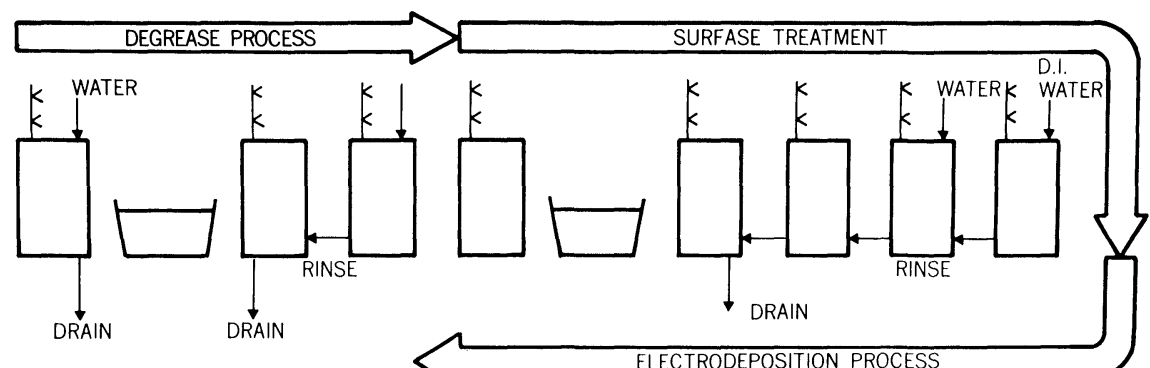

ig. 12.

An example of coating process.
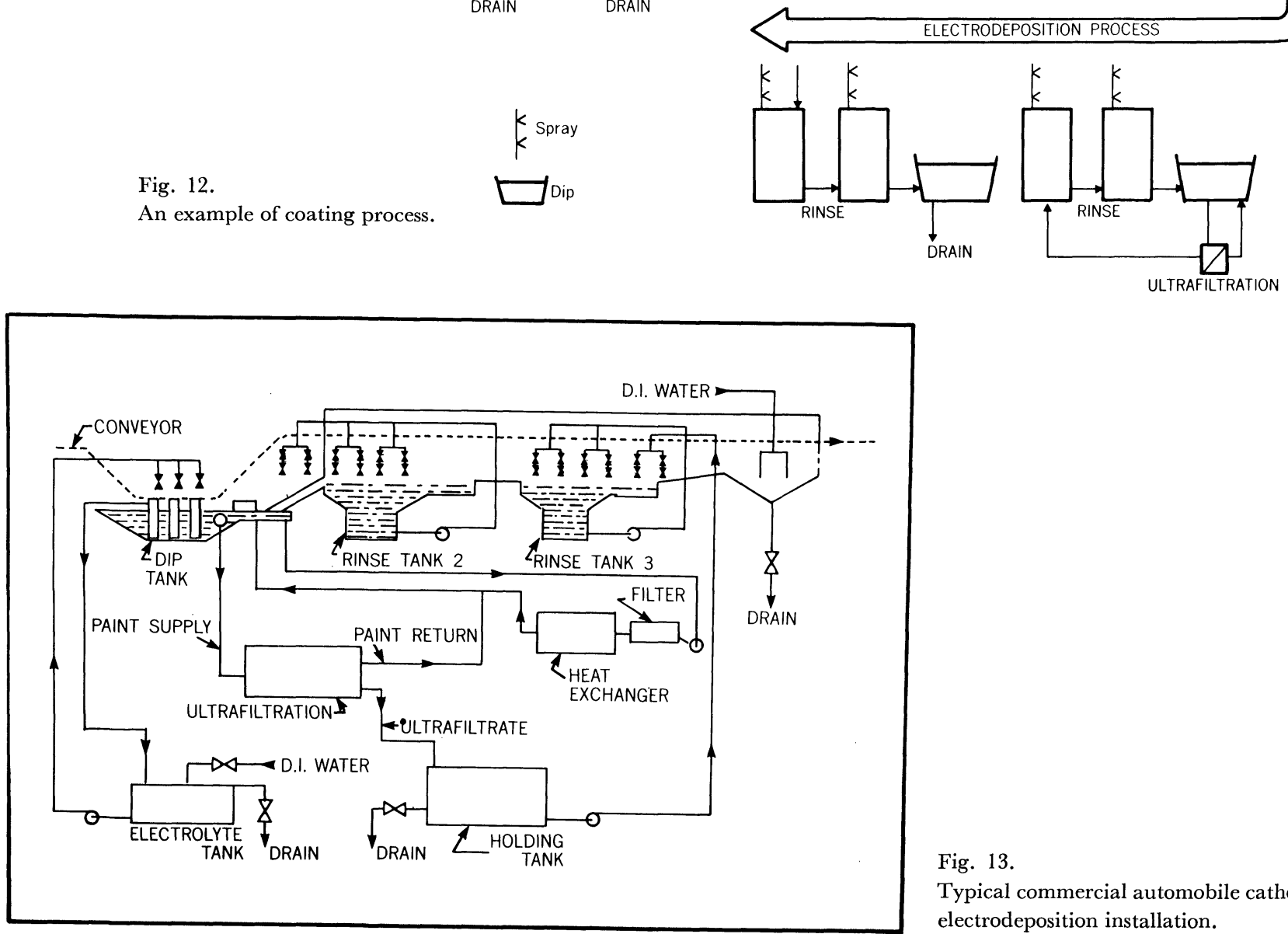

Fig. 13.

Typical commercial automobile cathodic electrodeposition installation. 
coating system will be applied to the small production line in addition to the mass production line such as automobile bodies one.

\section{3. $p H$ Control of Electrodeposition Bath}

When macroion to form the electrodeposition film is removed from the paint bath, counter ionic species remain in the deposition tank. This leads to the change of $\mathrm{pH}$ and electrodeposition coating can not be continued. Therefore, the status that the electrodeposition coating process has succeeded in the industrial line relies on the development of $\mathrm{pH}$ control methods. The following methods have been developed up to date.

(1) Neutralizer deficient resin feed system

The limited resins are used for cationic electrodeposition. This has been widely accepted in anionic electrodeposition coating system.

(2) Diaphragm system

Counter ionic species is accumulated in the diaphragm cell installed the counter electrode. And neutralizer is removed from the electrodeposition paint by pumping out this liquid in the diaphragm cell. This has been widely accepted in cationic electrodeposition coating system.

(3) Ion exchange method

Counter ionic species is removed from the paint liquid by using ' ion exchange resin'. This has been applied to a few automobile bodies line.

(4) Dialysis or electrodialysis method

This has been only accepted as a subsidiary method.

(5) Ultrafiltration system

This method is very useful because of the possibility of the continuous running, but the cost of the waste treatment is high.

In any method mentioned above, the actual control of the bath is based on the chemical analysis to keep the paint suitable compositions. The further improvement will be expected to enhance its rational control.

\section{Renewal of Electrodeposition Bath}

The application of ultrafilter for the renewal of the electrodeposition bath has been rapidly accepted in the industrial line. Ultrafiltrate will not be colored, but it has a high biochemical oxygen demand (BOD) and chemical oxygen demand (COD), therefore waste treatment is inevitable before discard. (Table 7)

Ultrafiltrate contains some non-electrolytes such as additives which are essential for the film forming; therefore, the filtrate will not be discarded from a standpoint to remove undesirable ionic species.

Ionic species which are brought from the prior tank, and decomposition compounds in the resin which are inevitably involved during the resin preparation accumulate in the deposition tank. They deteriorate the deposition efficiency and provide a poor film appearance. They also lower the effect of counter ions which help colloidal particles composed of film forming materials to stabilize. In the worst case, they lead to the aggregation of the paint. When the paint is treated by ion exchange method, its origi-
Table 7. An example of ultrafiltrate composition. ${ }^{20)}$

\begin{tabular}{|c|c|c|c|}
\hline & & Anionic & Cationic \\
\hline \multicolumn{2}{|c|}{ Solid (\%) } & 0.40 & 0.50 \\
\hline \multirow{4}{*}{$\begin{array}{c}\text { Solvent } \\
(\%)\end{array}$} & Cellosolve & 2.50 & 0.90 \\
\hline & Alcohol & 0.50 & 1.80 \\
\hline & Ester & - & 1.20 \\
\hline & Total & $3.00 \sim 3.50$ & 4.00 \\
\hline \multirow{2}{*}{\multicolumn{2}{|c|}{ Neutralizer (\%) }} & Organic amine & Organic acid \\
\hline & Water (\%) & 96.20 & 95.31 \\
\hline \multicolumn{2}{|c|}{$\mathrm{COD} \mathrm{Mn}(\mathrm{mg} / l)$} & $25000 \sim 30000$ & $30000 \sim 45000$ \\
\hline \multicolumn{2}{|r|}{$(\mathrm{mg} / l)$} & $10000 \sim 20000$ & $20000 \sim 35000$ \\
\hline
\end{tabular}

nal function recovers. However, if the paint is not treated suitably, there will cause the following damages.

(1) If ionic species possessing the same polarity as the counter ion is removed in excess, the paint aggregates. This treatment failure can not be absolutely permitted.

(2) Ionic species possessing opposite polarity (the same polarity as macromolecular ion) are allowed to contain in comparatively excess, and they play a key role of paint materials. Under some limited conditions, undesirable ionic species contribute to increase the conductivity of the paint which is essential for throwing power. If they are removed, throwing power lowers.

(3) If ionic species such as $\mathrm{CrO}_{4}^{2-}$ which are added to improve the corrosion protection of the film are removed, the film performance against corrosion deteriorates.

If throwing power is high enough and the resin possesses high corrosion resistance without anticorrosive pigment, it is allowed to remove ionic species completely. The removal of ionic species by ion exchange method is easy. It is possible to remain desirable ionic species in the deposition tank by utilizing ion selectivity of exchange resin; therefore, it will be expected to develop the utility of ion exchange method for electrodeposition coating system.

Ultrafiltration is popularly known as the method to measure the size of colloidal particles. Ultrafiltration collects the colloidal particles while passing through low molecular weight compound, solvent and ionic species. The pore size of ultrafilter is various and it is selected properly corresponding to the size of the colloidal particles. Ultrafilter does not work to segregate the counter ion for macroion. The counter ionic species under the chemical equivalent amount of neutralization can not pass through itself. As the ultrafilter does not have the ion selectivity, the filtrate keeps an equivalent balance of cation and anion. This indicates that various low molecular weight materials other than inherent ionic species pass ultrafilter.

On the other hand reverse osmosis collects the particles, which results in osmotic pressure. In contrast to ultrafilter which pass dissolved inorganic salts, re- 
verse osmosis reject the passage of ionic species.

It is recommended to use various combinations of systems mentioned below as corresponding to the purpose. The proper supply of the paint is shown in (1) of Fig. 14 and the combination among (2) (6) will be selected.

\section{Themes on Electrodeposition Coating Process for Automobile Bodies}

The reasons of industrial use of the electrodeposition process are its economical and mass production besides its film performance. When the real figure of the electrodeposition coating process is to be considered, the anti-corrosive design of automobile bodies must be involved. The anti-corrosive design is the key technology. The present status and the possible future development is described below. The performance of the primer obtained by the present electrodeposition technology for automobile bodies would not be dully satisfactory with. In order to discuss this essential theme logically, film performances, engineering process and coating methods are referred to.

\section{Film Performances}

Though film performances being demanded differ in the location of automobile bodies, the following three items would be future themes.

(1) Prevention of steel parts constructing engine room from oxidation reaction

(2) Corrosion protection of skirt parts with the defect area in the film

(3) Film adhesion to precoated steel in particular film adhesion under wet-dry cycle test

In theme (1), organic materials would not fit for coating, even if the ones containing silicon compounds are developed. They will not put up with the high temperature because of the limited thermal stability of chemical carbon bonds, therefore the application of inorganic materials would approach to steel parts.

In theme (2), corrosion types must be considered. The corrosion arises from the defect part (local corrosion) due to the drop in a penetrating coefficient of water and corrosive gas through film and due to the increase of film adhesion. The real life of the constructed steel is the power, which maintains the initial strength steel constructs as long as possible. By film performances, it is essential to prevent the rapid drop in the strength caused by local corrosion, though it goes without saying that the film prevents the steel from uniform corrosion. This concept is shown in Fig. 15.

In theme (3), the precoated steels plated with various metals have been produced by the demand for the design of automobile bodies. The steel produced by Continuous Annealing and Pickling Line is different from Batch Process in terms of the quantity of minor elements added into the steel. In the precoated steel, as the plated metal is usually more active than iron, its oxidation reaction under priming conditions affects the nascence and rate of corrosion reaction. Accordingly, the role of phosphate coating and its crystal composition would be necessary to be analyzed in

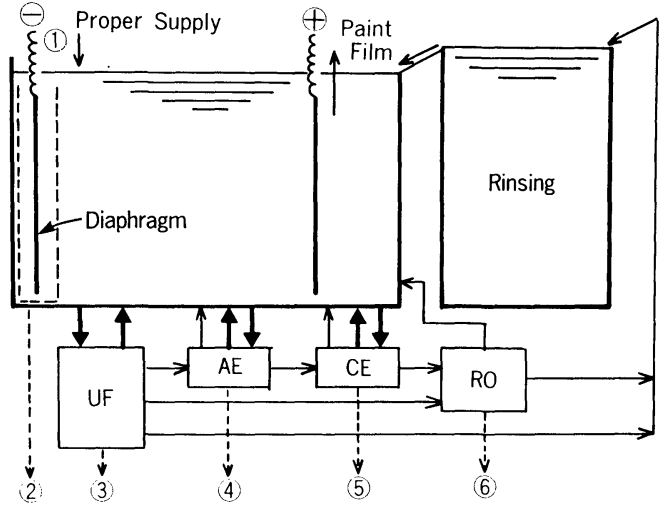

(1) Neutralizer deficient resin feed system (proper supply)

(2) Diaphragm system

(3) Ultrafiltration system

(4) Anion exchange method

(5) Cation exchange method

(6) Revers osmosis system

Fig. 14. Various renewal systems.

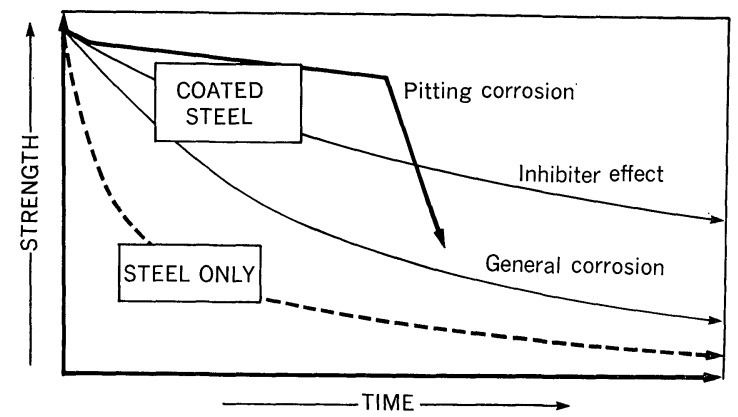

Fig. 15. A model of the strength deterioration of steel materials due to corrosion.

combination with characteristics of precoated steel and corrosion environment under primer.

In the steel containing minor elements, minor elements affect the core of phosphating growth and its crystal form. They would be also essential to be analyzed in combination with characteristics of steel surface.

\section{Primer Coating Process for Automobile Bodies}

At present, the coating process has been generally accomplished. However, the following themes from electrodeposition coating process would be necessary to be dissolved.

\section{Throwing Power and Coating Thickness}

Electrodeposition coating has established in a large place as a primer for automobile bodies relying mainly on the superiority of throwing power.

However, the recessed parts (e.g., the inside of door part) remain unpainted virtually by the present electrodeposition coating process. As described in Chapter $I I I$, the increase in film thickness is tend to the decrease in throwing power. It would be attained to enhance remarkably their both performances (that is, the ability to increase in film thickness and the ability to coat fully up to the united parts) either by utilizing the mixture of more than two paints which they differ 
largely in the film formation mechanism each other or by some devices relating to the deposition method (this implies the method of power supply and the design of the deposition tank).

According to the present technology, we believe that the methods mentioned above cause negative factors in any of mass production, process control and film performance. It is rather important to approach from standpoints how the design of automobile bodies would be improved in terms of corrosion resistance and how the expected film performance could be achieved. In cases, the use of pre-coat metal for automobile bodies will be partially realized.

\section{Theme Arising from Cation Process}

The cationic electrodeposition process holds many advantages in a point of corrosion protection in comparison to anionic one. That is,

(1) The metal does not dissolve from the cathode (the object) when the voltage is applied.

(2) The film has the anion selective permeability and it prevents the permeation of cationic species when it is exposed to corrosive environment.

Surfacer and top coat possessing plenty of carboxyl groups are usually anion selective film, so both anion and cation species are prevented to permeate threecoat film. And it affects the lowering of electric resistance of film and acccrdingly it affects corrosion resistance. On the other hand, cation electrodeposition process holds following disadvantages.

(1) The deposition tank acts as the anode during electrodeposition. This causes the dissolution of the metal from the tank (the deposition voltage applied is over decomposition one of iron). Therefore, some engineering devices such as the lining of the tank and the installation of the stainless steel electrode are necessary.

(2) The paint is acidic, causing corrosion of the whole installations of the process, therefore the corrosion protection in any of installations are essential.

(3) Hydrogen emits from the cathode (the object). Since the cold-rolled steel is utilized now, the deteriolation by hydrogen embrittlement is negligille. If hightensile steel is utilized, various devices to prevent hydrogen embrittlement may be inevitable.

\section{Theme on Coating Process}

\section{Paint Supply and Control of Paint Tank}

In the present industrial coating line, the paint supply and the control of paint tank are performed efficiently. But there would be left some means to rationalize.

The rate limiting factors of the use of automation control by a computer would be analyses in the relation between chemical informations of the paint and physical ones of the electrodeposition coating process. By clarification of the mechanism of throwing power and it is believed that this would be an analysis in factors including geometrical conditions besides paint conditions in the industrial line. The automation control could be realized from the viewpoint of the investment needed to do it in contrast to the cost decrease by saving labor. It would be valuable to reas- sess it owing to the cost decrease of micro computer, through every industrial coating lines possess the different characters.

\section{Ambient Control in Baking Furnace}

The problem that the tar arised from evaporated material from paint in the baking furnace dropped to the automobile bodies has happened. This essentially belongs to the theme relating to the devices such as furnace structure (implies thermal efficiency) and process engineering. On the other hand, this also belongs to the theme on paint compositions subsidiary.

\section{Theme on the Materials for Automobile Bodies}

The new materials such as plastics and precoated metal may be taken up from the view point of corrosion protection of bodies. As more than two different metals are contracted at the welding areas, the corrosion reaction is promoted there. It will be necessary to coat the substrate with the high electric resistance film and superior adhesive paint.

\section{Conclusion}

In this review on the electrodeposition coating process technology for automobile bodies, its short history, mechanism, throwing power, resins and process were described in Chapters $I$ to $V$, respectively and in Chapter $V I$, themes on problems on the basis of the authors' views were described. When the automobiles produced in the largest mass industrially are viewed from a standpoint of corrosion protection, it is quite right to say that this theme should be solved by the total technology of the substrate steel, phosphate coating, electrodeposition coating. As long as the steel is utilized and the commercial value of automobiles is largely occupied by hue and appearance, the coating is inevitably essential. The electrodeposition coating plays a key role for durable years of automobile bodies. Electrodeposition process will be continued to be used for automobile bodies on the basis of many advantages such as economical value, easy quality control and easy automation control.

Paradoxically, if the electrodeposition coating process could not be improved to cover up to the fine performance in a point of total corrosion protection design, it may be possibly substituted for other process. The trigger of substitution will be pushed by the problems from relatively sober spheres such as the answer to the recessed parts and to the welding areas. From a large point of view, it will rely on the logical thinking of the protection role of precoated metal and coating against corrosion. In other words, it will rely on whether they will perform differently their functions based on their guide principles of corrosion protection or not.

\section{REFERENGES}

1) N. Furuno, H. Kawai and Y. Oyabu: Shikizai Kyokaishi (J. Japan Soc. Colour Material), 45 (1972), 564.

2) A. M. Usami: Polym. Plast. Tech. Eng., 15 (1980), 115.

3) Y. Oyabu: J. Metal Finishing Soc. Japan, 28 (1977), 306.

4) D. G. Anderson, E. J. Murphy and J. Tucci: J. Coat. Tech., 
50 (1978), No. 646, 38.

5) A.R.H. Tawn and J. R. Berry: J. Oil Colour Chem. Assoc., 48 (1965), 790.

6) N. Furuno, H. Kawai and Y. Oyabu: Shikizai Kyokaishi (J. Japan Soc. Colour Material), 42 (1969), 362.

7) N. Furuno, H. Kawai and Y. Oyabu: J. Colloid Interface Sci., 55 (1976), 297.

8) N. Furuno and Y. Oyabu: Prog. Org. Coat., 5 (1977), 201.

9) P. E. Pierce: J. Coat Tech., 53 (1981), No. 672, 52.

10) M. Wismer, P. E. Pierce, J. F. Bosso, R. M. Christenson, R. D. Jerabek and R. R. Zwack: J. Coat Tech., 54 (1982), No. $688,35$.
11) F. M. Loop: Corrosion '80, Assoc. Corro. Eng., Chicago, March (1980), Paper No. 125

12) P. I. Kordomenos and J. D. Nordstorm: J. Coat Tech., 54 (1982), No. 688, 33.

13) U.S. Patent No. 3853803, (1974).

14) U.S. Patent No. 4148772, (1979).

15) U.S. Patent No. 4172193, (1979).

16) U.S. Patent No. 4134832, (1979).

17) U.S. Patent No. 3823118, (1974).

18) U.S. Patent No. 4138377, (1979).

19) U.S. Patent No. 3617458, (1971).

20) S. Honda: Nissan Giho, 17 (1981), 211. 